\title{
Access Services Based on MHP Interactive Applications
}

\author{
Carlos Alberto Martín, Lara García, José Manuel Menéndez, Member, IEEE, \\ and Guillermo Cisneros, Member, IEEE
}

\begin{abstract}
In this paper it is described how interactive applications can be used to provide access services for people with disabilities in digital television.

MHP (Multimedia Home Platform) is a standardized middleware to develop interactive applications in digital television. In this way, the interactive applications become tools for the provision of the access services.

These features have been exploited in a research project to create a subtitle application for the deaf and hard of hearing people and an accessible electronic program guide for blind people ${ }^{l}$.
\end{abstract}

Index Terms - access services, interactive application, accessibility, MHP, people with disabilities

\section{INTRODUCTION}

This paper explains how MHP interactive applications can be used to provide access services in digital television.

MHP (Multimedia Home Platform) is the DVB standard for interactive applications [1]. MHP applications are broadcasted together with the rest of transport stream components (video, audio and data) inside a data structure called DSM-CC carousel type B, according to MPEG-2 part 6 [2]. A standard, open technology like MHP ensures interoperability between the different steps in the value chain.

In this way, application developers do not need to write the same interactive service for each platform; broadcasters certainly know that consumers will be able to enjoy any interactive content delivered and buy the set-top box they prefer.

MHP consists of a middleware, i.e. an abstraction layer that allows interactive applications to use the set-top box resources, such as RAM memory or graphical performance. Thus, the middleware offers an API (application program

\footnotetext{
${ }^{1}$ This work was supported in part by the Spanish Ministry of Industry, Tourism and Trade (FIT-350300-2007-97 and TSI-020100-2008-212)

C. A. Martin is with the Universidad Politécnica de Madrid - Grupo de Aplicación de Telecomunicaciones Visuales (G@TV). ETSI de Telecomunicación. Ciudad Universitaria s/n. 28040 Madrid (e-mail: cam@gatv.ssr.upm.es).

L. García is with the Universidad Politécnica de Madrid - Grupo de Aplicación de Telecomunicaciones Visuales (G@TV). ETSI de Telecomunicación. Ciudad Universitaria s/n. 28040 Madrid (e-mail: lgv@gatv.ssr.upm.es).

J. M. Menéndez is with the Universidad Politécnica de Madrid - Grupo de Aplicación de Telecomunicaciones Visuales (G@TV). ETSI de Telecomunicación. Ciudad Universitaria s/n. 28040 Madrid (e-mail: jmm@gatv.ssr.upm.es).

G. Cisneros is with the Universidad Politécnica de Madrid - Grupo de Aplicación de Telecomunicaciones Visuales (G@TV). ETSI de Telecomunicación. Ciudad Universitaria s/n. 28040 Madrid (e-mail: gcp@gatv.ssr.upm.es).
}

interface), which is used by developers to program their applications.

These ideas are shown in Fig. 1. In vertical markets, a single company integrates all the steps of the value chain and a proprietary middleware can be used. However, in a horizontal market, which is usually the case of digital terrestrial television (DTT), a standard middleware is needed to ensure the interoperability between steps in the value chain and to reduce the set-top box deployment costs [3].

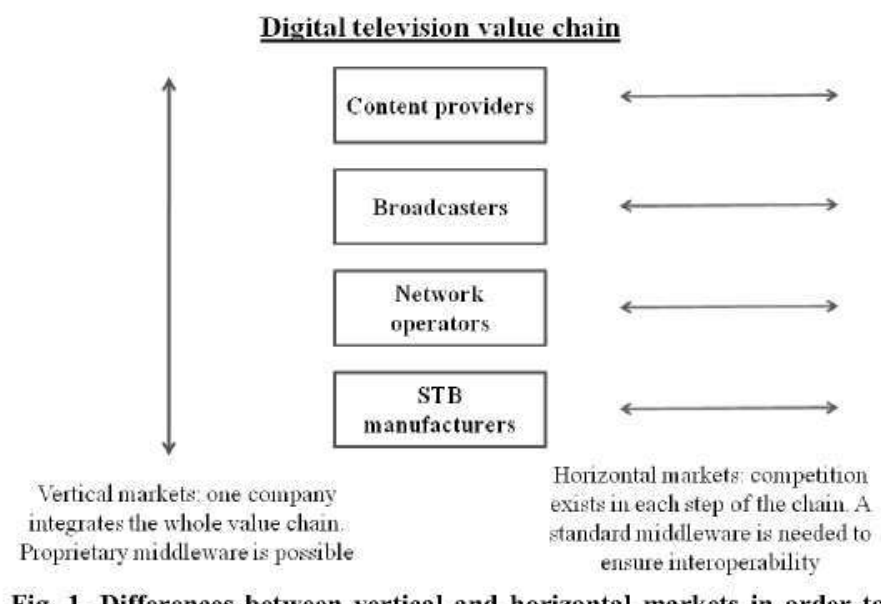

Fig. 1. Differences between vertical and horizontal markets in order to adopt a middleware for interactive applications in digital television.

A big number of interactive applications can be developed: information services, program guides, communication services, interactive advertising applications, games, etc. Thus, e.g., [4] explains a personalized TV system running on standalone set-top box (STB) compliant with MHP.

However, this paper proposes a novel way to take advantage of MHP: providing access services for people with disabilities. It must be taken into account that this issue is independent of the accessibility to the interactive applications.

The working group for accessibility of Spanish Digital Television Forum already identified this possibility of the MHP to be used as a tool to provide accessibility [5].

\section{GetTING ACCESSIBILITY}

\section{A. Access Services}

Access services make possible that people with disabilities enjoy the TV content. This is an important issue because ten per cent of the population in the world has a disability, according to United Nations data. Moreover, the number of elderly people is increasing in our societies. Elderly people usually have one or more disabilities in a certain degree. 
Some common access services, according to European Broadcasting Union, are subtitling, spoken subtitling, audio description and signing [6]. Close captioning is a good example of access service.

There are not only social reasons to provide access services. People with disabilities make up an enormous market that requires products and services. Moreover, an increasing number of countries are approving acts that specify compulsory access service quotas for public and private broadcasters.

\section{B. Project Objective}

The results explained in this paper have been obtained in a research project whose aim was to develop access services and tools for the different kinds of disabilities: deaf people, blind people, people with physical disability and people with intellectual disability. These technical developments became flags to show the digital television potential for accessibility.

\section{Reduced Flexibility in Set-top Boxes}

These services or tools must run on the set-top box. The lack of flexibility in set-top boxes was confirmed while implementing the research tasks of the project.

This reduced flexibility is due to several causes. Firstly, digital set-top boxes are devices prepared to receive audio and video signals in a transport stream. However, they are not always prepared to receive software to be executed. Some models of set-top boxes are equipped with a serial port that allows the developers to introduce the software. Unfortunately, that does not mean the software can be executed. They need an additional middleware compatible with the software introduced in order to execute it.

Due to the variety of operating systems, firmware and technical resources that may be present in this kind of devices, each manufacturer, even each model can implement its own API for the development of software. For this reason, the services and tools would have to be developed only for a particular model of set-top box.

Finally, the increasing tendency to integrate functionalities in chips also reduces the flexibility. This tendency has been noticeable in the consumer electronic industry for the last decades.

\section{MHP as a Solution}

A standard middleware, like MHP, is a solution for all these problems. MHP allows the insertion of software in the set-top boxes that are available actually in the consumer electronics market. Additionally, MHP implements security mechanisms to avoid the load of malicious software. Moreover, some MHP implementations allow the upload of applications by means of a serial RS-232 port, if present in the set-top box.

On the other hand, MHP was specifically designed to allow applications delivered by the broadcasters to be executed in set-top boxes.
Due to its open and standard features, MHP ensures interoperability. Therefore, application developers and broadcasters know how MHP services will behave in any settop box, independently of its manufacturer.

Thus, MHP allows any research group or company to develop software to be executed on receivers and to introduce this software in the set-top boxes in a standardized way, via DSM-CC carousels multiplexed in the broadcasted MPEG-2 transport stream [2].

MHP was chosen in this research project because it was the middleware adopted in Spain (and in many other countries in the world) for the DTT horizontal market. However, any other open or proprietary middleware may be used to provide access services, according to its features.

\section{E. MHP Features}

MHP was not conceived to develop access services for people with disabilities but it provides specific features that can be used in access service implementation.

One of the most important characteristics of MHP is its graphical riches. Developers can take advantage of this feature to provide specific services for deaf and hard of hearing people. On the other hand, this graphical power is not useful for the blind people. However, MHP also supports audio clips, which can be used to offer spoken information for blind and visual impaired people.

These features have been used in the research project as explained in the next section.

\section{IMPLEMENTED APPLICATIONS}

As an example of these features, two applications have been implemented in the research project. On the one hand, a subtitle application that can be configured by the deaf or hard of hearing person and, on the other hand, an electronic program guide with audio clips for blind people.

\section{A. Subtitle Application}

Although DVB-SUB (the standard provided by DVB to offer digital subtitles [7]) subtitles allow a high-quality graphical subtitle service in digital television with respect to the old teletext technology, they do not allow users to configure them. For this reason, we decided to implement a subtitle MHP application within the framework of the research project.

The MHP application programmed allows users with disability to configure four parameters, as shown in Fig. 2:

- Position of the subtitles in the screen.

- Transparency level of the subtitle box.

- Size of the letters.

- Font.

For this last feature, the application takes advantage of the technical resource called "downloadable fonts" in the MHP standard. In this way, fonts can be broadcasted with the application, achieving a great flexibility.

Fig. 3 shows a sample of these subtitles. In this example, the deaf or hard of hearing user would have chosen to put the 
subtitles at the top of the screen and a partially transparent box.

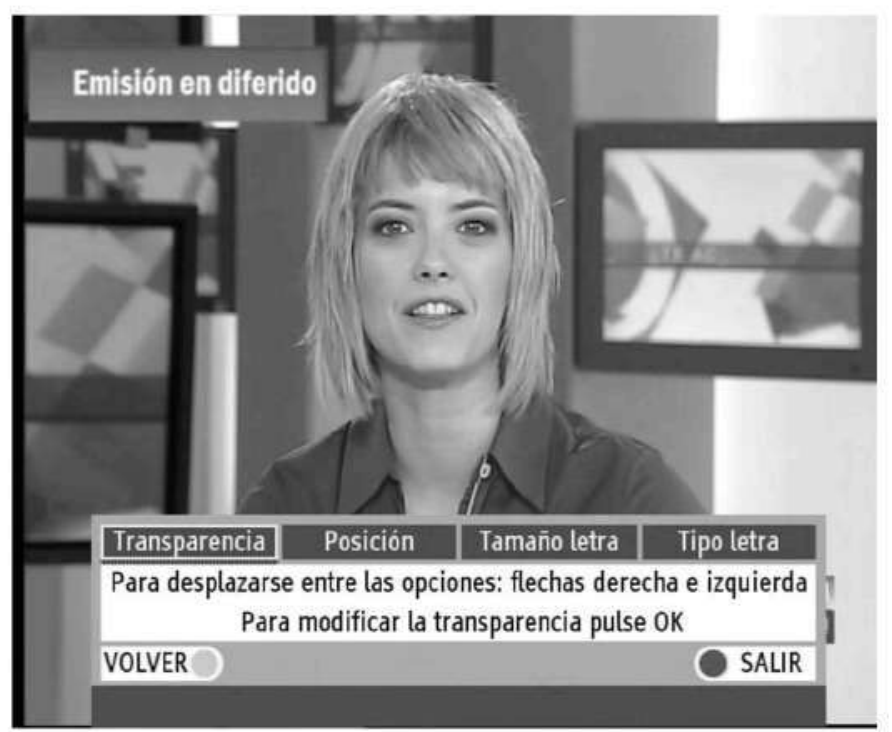

Fig. 2. Configuration screen in the subtitling application. The user can adjust four parameters.

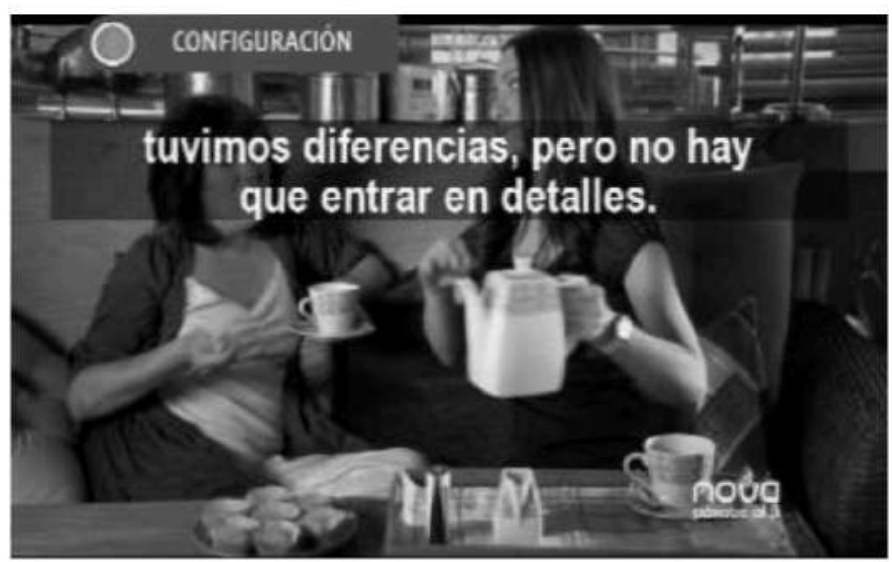

Fig. 3. Snapshot of the subtitling application. Subtitles are displayed according to user configuration.

The application renders the subtitles from text, which is multiplexed in private sections with a specific PID within the MPEG-2 transport stream. As text format is used, this data stream requires a very low bit rate (around $1 \mathrm{~kb} / \mathrm{s}$ for any kind of program). The MHP interactive application is able to filter the transport stream packets to extract the private sections and displayed the subtitles.

The main added value of this application is to allow users to configure subtitles according to their tastes and preferences, in order to provide a completely satisfactory service for deaf and hard of hearing people.

\section{B. Accessible program guide}

TV navigation systems make it easier for viewers to find and watch TV programs, as described in [8].

However, the proliferation of electronic program guides, browsers and other graphical interfaces to select the channels in digital television can suppose the absolute inaccessibility of digital television for the blind and visual impaired people. A new access service is required in order to supply some audible feedback to people with a visual disability when using tools to zap or choose channels. This new service might be named "audio navigation".

To provide the audio navigation service and avoid the risk of absolute inaccessibility to the digital television, an accessible electronic program guide was developed within the project. This guide takes advantage of the feature of MHP to play audio clips. In this way, the names of the channels are spoken by the application. Files containing human voice are sent together with the guide.

To satisfy these functionalities, the accessible program guide is able to know the signalization data about the TV services, according to DVB service information norm [9]. MHP includes methods to get this information.

Fig. 4 shows how the developed program guide can be used as a conventional EPG but it adds the value of playing the name of the channels when the user browses through the channel list. Radio channels are also available.

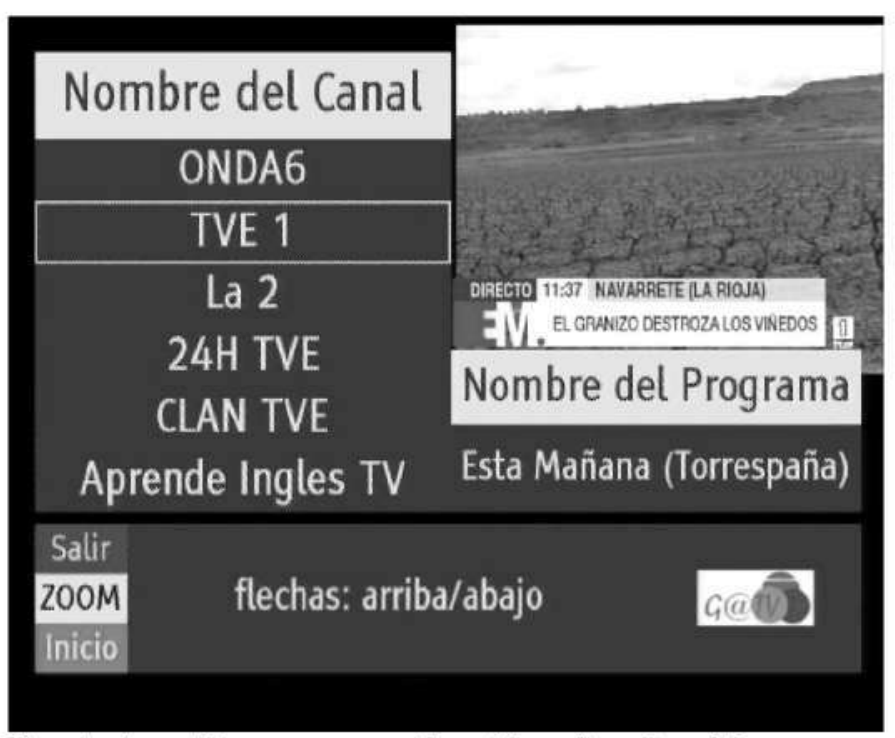

Fig. 4. Accessible program guide with audio clips. Moreover, an accessible graphical interface is used.

When the user listens to the name of the channel he or she wants to watch, he or she must simply push the OK button in the remote control.

On the other hand, the application is able to play the name of the channel when the user pushes the program buttons or the numerical keyboard in the remote control. This is a second way of working. In this case, the graphical interface of the accessible program guide is not used, although a graphical feedback is provided for a few seconds, as shown in Fig. 5.

It is important to notice that the graphical interface has been designed for partially visual impaired people. For this reason, a big letters size, an accessible font and a suitable color combination are used. Moreover, this color combination is valid for almost all the kinds of color blindness. 


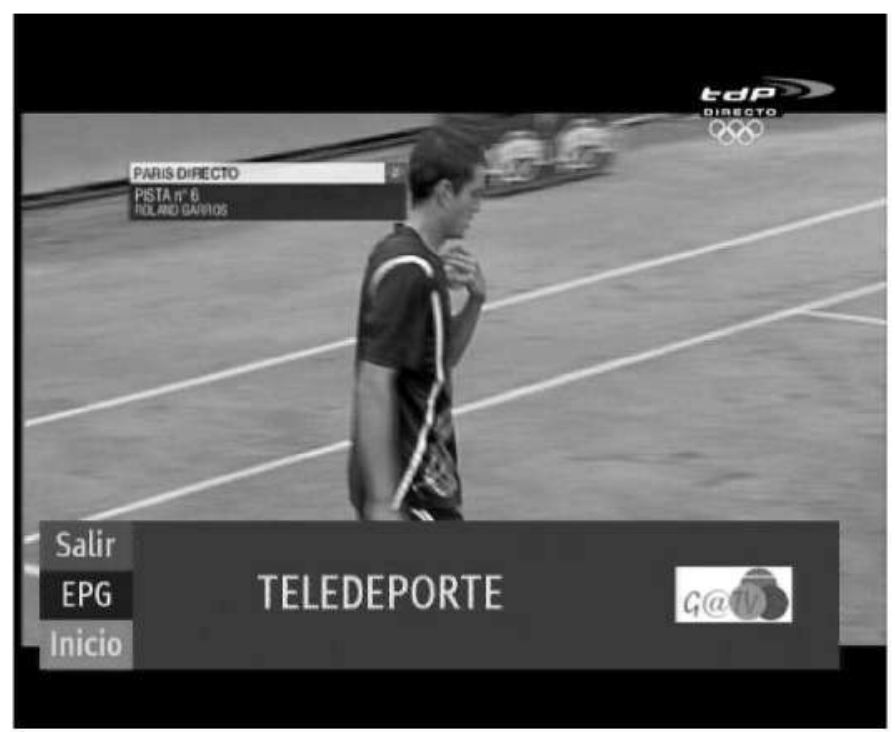

Fig. 5. A graphical and audible feedback is provided if the user presses directly the button of the remote control to choose the channel.

\section{PRoBlems IN MHP DEPLOYMENT}

In spite of the new business opportunities based on interactive applications and its potentiality to offer new services for the citizens, MHP has not reached the expected deployment in most of the countries. There are several reasons for that.

Digital television set-top boxes are consumer electronic devices which must minimize its price in order to be competitive in the market. However, the execution of MHP in the set-top boxes requires hardware that makes them more expensive in comparison with non-interactive receivers. For this reason, consumers prefer receivers without interactive performance when they purchase a receiver in the distribution chain.

On the other hand, citizens do not know the full features of interactive digital set-top boxes. Perhaps, authorities have avoided issues such as interactivity or high definition during the information campaigns for the deployment of digital terrestrial television in Europe in order not to cause confusion among the population.

Finally, another problem related to MHP must be explained. Companies that participated in the elaboration of the standard asked some years later for royalties due to the inclusion of patented technologies in MHP. Thus, it was a case of submarine patents. Although this fact was solved, it caused the loss of the broadcasters' support.

In spite of these problems in MHP actual deployment, the thesis of this paper remains valid: the potentiality of interactive application middleware (maybe MHP, maybe any other) to provide access services for people with disabilities.

\section{Conclusion}

The work carried out in the project has demonstrated how the potentiality of digital systems to create and integrate new services can be used to provide accessibility for people with disabilities in digital television. Particularly, the project has taken advantage of MHP applications. Although MHP future is threatened due to some problems, these ideas can be carried to any other middleware, according to its features.

\section{ACKNOWLEDGMENT}

The authors thank our colleagues in UPM who participated in the development of the MHP applications and the related software: María Alduán, Javier Arjona, José María Merchán and Olgen Hoxha.

Finally, the authors thank the CESyA (Spanish Center for Subtitling and Audiodescription) for making possible a professional graphic design for the subtitling application.

\section{REFERENCES}

[1] European Telecommunications Standards Institute (ETSI). "Digital Video Broadcasting (DVB); Multimedia Home Platform (MHP) Specification 1.0.2." (DVB-MHP 1.0.2) 2005. ETSI TS 101812 V1.2.1. 2005

[2] ISO/IEC International Standard 13818-6:1998, "Information technology - Generic coding of moving pictures and associated audio information -Part 6: Extensions for DSM-CC (Digital Storage Media Command and Control)"

[3] G. O'Driscoll, The essentiel guide to digital set-top boxes and interactive TV, Prentice-Hall, Inc.: Upper Saddle River, reprinted April, 2000, p. 82

[4] Hongguang Zhang, , Shibao Zheng, and Jianghai Yuan, "A Personalized TV Guide System Compliant with MHP," IEEE Trans. Consumer Electron., vol. 51, no. 2, pp. 731-737, May. 2005.

[5] Working group 5 for accessibility of the Spanish Digital Television Technical Forum, "Accesibilidad en Televisión Digital para personas con discapacidad," ("Accessibility to the Digital Television for people with Disabilities") Spanish Ministry of Industry, Tourism and Trade, Madrid 2006.

[6] European Broadcasting Union (EBU), EBU report on access services, EBU Technical Information I44-2004, June 2004.

[7] European Telecommunications Standards Institute (ETSI). "Digital Video Broadcasting (DVB); Subtitling systems,” (DVB-SUB) ETSI EN 300743 V1.3.1. 2006

[8] Tadashi Isobe, Masao Fujiwara, Hiroyuki Kaneta, Noriyoshi Uratani, and Toshiya Morita, "Development and features of a TV navigation system," IEEE Trans. Consumer Electron., vol. 49, no, 4, pp. 1035-1042, Nov. 2003.

[9] European Telecommunications Standards Institute (ETSI). "Digital Video Broadcasting (DVB); Specification for Service Information in DVB Systems," (DVB-SI) ETSI EN 300468 V1.11.1 2009

\section{BIOGRAPHIES}

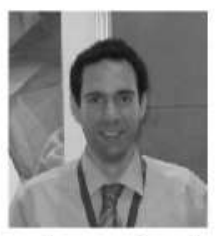

Carlos Alberto Martín received the Telecom Engineer degree (Hons.) by the Universidad Politécnica de Madrid in 2004. Currently he is a $\mathrm{PhD}$ candidate. $\mathrm{He}$ is a specialist on digital television, the area of knowledge to which he is aiming his research (audience measurement, MHP interactivity, DVB system engineering and accessibility for people with disabilities). He was an active member is several working groups of the Spanish Digital Television Forum. He has worked in several national and European projects and has been the technical manager in some of them. Finally, he is a member in several working groups of the Spanish Association for Standardization and Certification. 
Lara García received the Telecom Engineer degree (Hons.) in 2007 from the Universidad Politécnica de Madrid. Since 2007, she is a Ph.D. candidate and researcher assistant at the Visual Telecommunications Application Group within the Signals, Systems and Radio communications Department. She has participated in several national and international research projects. Her research activity is based on interactive applications for digital television based on the DVB-MHP standard, P2P content management systems and accessibility to digital television for people with disabilities. She has several publications in national and international conferences.

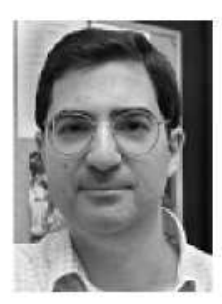

José Manuel Menéndez received the Telecom Engineer degree (Hons.) in 1988 and the $\mathrm{Ph} . \mathrm{D}$ degree in Communications (summa cum laude) in 1996, both by the Universidad Politécnica de Madrid. Since 1988 he is a member of the Signals, Systems and Radio communications Department of the E.T.S. Ingenieros de Telecomunicación, becoming associate professor in 1996. His professional interests include computer vision, image processing, digital video broadcasting and visual communications. He has been actively 13 involved both in European (Eureka, Race, Esprit, ACTS, and IST, since the II FP) and in national projects since 1988. Dr. Menéndez has about 40 international publications, both in international journals and conferences, and is also member of CEN/278 WG1 for the topic of Telecommunications and video technology applied to Intelligent Transportation Systems.

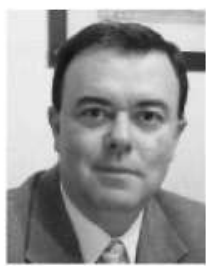

Guillermo Cisneros received the Telecom Engineer degree (Hons.) in 1983 and Ph.D in Communication Engineering cum laude in 1986, both from the Universidad Politécnica de Madrid. He is Full Professor of Telecommunication Systems, lecturing on Multimedia Networks, Systems and Services, Digital Image Processing, Image Coding and Analysis, and Computer Graphics. Besides of his lecturing and research activities at the University, he joined Telefónica of Spain for a decade working in technical, managerial, and international business responsibilities in research and mobile communications. He was Spanish representative in different International Organisations and Working Groups, such as IWP 11/4 of the former CCIR (now UIT-R), GSM, and MoU for GSM establishment. He has also been active participant in several European Projects of different EU Programmes, with strong technological and consortium managerial responsibilities, mainly in the areas related to Networked Electronic Media. Currently, he is Director of E.T.S. Ingenieros de Telecomunicación of Universidad Politéenica de Madrid. 